\title{
SIMBOL LESBIAN DALAM NOVEL GERHANA KEMBAR KARYA CLARA NG
}

\section{OLEH}

\author{
Adryan Nur Alam ${ }^{1}$, La Ode Syukur ${ }^{2}$, dan Sumiman Udu ${ }^{3}$ \\ ${ }^{1}$ Alumni Jurusan Pend. Bahasa dan Sastra Indonesia, ${ }^{2,3}$ Dosen Jurusan \\ Pendidikan Bahasa dan Sastra Indonesia, Fakultas Keguruan dan Ilmu \\ Pendidikan Universitas Halu Oleo
}

\begin{abstract}
ABSTRAK
Penelitian ini dilatarbelakangi oleh maraknya lesbianisme yang sering terjadi dalam masyarakat, sehingga dengan mengidentifikasi makna-makna simbol lesbianisme dalam novel Gerhana Kembar karya Clara Ng ini kita dapat mengambil nilai-nilai pendidikan yang terkandung di dalamnya, dimana dengan diketahuinya simbol-simbol lesbian dapat menjadi acuan atau patokan untuk orang-orang terdekat kita bagaimana melakukan pengawasan tentang perilaku yang hampir mendekat ke arah lesbian tersebut. Penelitian ini bertujuan untuk Untuk mengetahui dan mendeskripsikan Simbol Lesbian dalam Novel Gerhana Kembar karya Clara Ng. Metode yang digunakan dalam penelitian ini adalah metode deskriptif kualitatif, dengan data penelitian berupa kata-kata, percakapan dan kalimat dalam bentuk ungkapan yang mengandung tanda dan simbol lesbian dalam novel Gerhana Kembar karya Clara Ng. Data dalam penelitian ini dianalisis menggunakan pendekatan semiotik menurut Roland Barthes. Berdasarkan hasil analisis data dan pembahasan diperoleh kesimpulan bahwa, lebian dalam Novel Gerhana Kembar dianalisis berdasarkan 5 kode yaitu berdasarkan kode Hermeneutik yang menunjukkan asbabun nuzul atau sebab akibat terjadinya lesbian yang dilakukan oleh Henrietta dan Fola sebagai akibat selalu mempunyai waktu bersama, kemudian melalui kode konotatif atau kilasan makna yang menunjukkan atas kebersamaan Henrietta dan Fola mereka mulai menyatakan apa yang mereka rasakan melalui beberapa kilasan makna, kode simbolik yang menunjukkan tanda atau symbol yang hanya mereka mengerti sendiri bahwa Henrietta maupun Fola menyukai sesama jenis, selanjutnya adalah kode proaretik atau tindakan yang mereka lakukan sebagai ungkapan perilaku lesbian mereka, dan yang terakhir adalah kode Gnomik atau kultural yang menunjukkan kebudayaan yang selaras dalam latar novel Gerhana kembar.Kemudian tindakan lesbian tersebut bertentangan dengan nilai agama dan norma sosial yang dimana masyarakat indonesia masih menganggap tabu persoalan perilaku lesbian.
\end{abstract}

\section{Kata Kunci : makna, simbol, lesbian}

354 | Jurnal BASTRA (Bahasa dan Sastra), Vol. 4 No. 2, Edisi April 2019/e-ISSN: 2503-3875/ http://ojs.uho.ac.id/index.php/BASTRA 


\section{PENDAHULUAN}

\subsection{Latar Belakang}

Karya sastra merupakan karya kreatif yang diciptakan oleh manusia, dan bahasa digunakan sebagai mediumnya. Karya sastra juga digunakan sebagai sarana hiburan bagi pembaca. Saat membaca karya sastra, pembaca akan memperoleh kepuasan tersendiri.

Karya sastra mengandung unsur keindahan yang dapat menimbulkan perasaan senang, nikmat, terharu, menarik perhatiaan dan menyegarkan penikmatnya. Hal ini sesuai dengan pendapat yang dikemukakan oleh Horace dalam Wellek dan Warren (2013: 25) bahwa hakikat dan fungsi seni harus dikaitkan pada dulce et utile yang artinya indah dan berguna. Dua istilah tersebut mempunyai kaitan yang erat untuk memahami makna sastra secara keseluruhan.

Novel Gerhana Kembar yang berisi tentang kehidupan seorang lesbian, kini tidak lagi dianggap tabu. Kenyataan bahwa komunitas tersebut ada dalam masyarakat mampu dihadirkan dalam sebuah cerita. Lesbian yang termasuk dalam homoseksualitas mengacu pada interaksi seksual atau romantis antara pribadi yang berjenis kelamin sama. Lesbian adalah suatu istilah tertentu yang hanya digunakan pada wanita homoseks.

Realita tentang lesbianis tidak menyurutkan niat Clara $\mathrm{Ng}$ untuk tetap membuat sebuah novel yang bertajuk lesbian, yang kemungkinan akan menjadi sorotan bagi masyarakat luas. Dalam novel Gerhana Kembar ini ia dengan terbuka menguak mengenai masalah lesbianisme. Ia memaparkan bagaimana kehidupan wanita yang mencintai seorang wanita dengan ketulusan hatinya. Bagaimana perjuangan kedua wanita tersebut untuk tetap memegang utuh rasa cinta mereka tanpa menyakiti orang lain dengan berusaha untuk menahan rasa yang bergejolak di dalam diri mereka masing-masing. Novel tersebut juga menggambarkan dengan jelas bagaimana kedua wanita tersebut memiliki pergolakan batin atas rasa yang ada di dalam diri mereka, kesakitan, perasaan bersalah, kerinduan yang mendalam akan keinginan untuk bisa bersama.

Clara $\mathrm{Ng}$ menampilkan sosok Fola yang memiliki perjuangan luar biasa akan cinta yang dirasakannya terhadap Henrietta, yang mana dia selalu berusaha untuk bisa memperjuangkan haknya agar bisa bersama-sama dengan Henrietta. Namun menariknya Clara $\mathrm{Ng}$ dalam Novel ini menyajikan karakter seorang Fola yang tidak egois dengan keinginannya saja sehingga akhirnya Fola harus tetap menjalani hidupnya dengan perasaan yang harus ditahan karena dia tidak hanya memikirkan dirinya sendiri. Novel ini Juga menampilkan bahwa seorang lesbian bukanlah sosok seperti yang direpresentasikan selama ini. Clara $\mathrm{Ng}$ dengan jujur meletakkan dan mencoba mendeskripsikan dengan lembut bagaimana perjuangan yang dihadapi seorang lesbian untuk dapat diterima dalam lingkungan sosialnya. Pendeskripsian hubungan secara lebih intim yang dilakukan oleh kedua wanita tersebut tidak di umbar secara frontal namun pembaca akan mampu melihat dan merasakan pergolakan cinta yang dirasakan oleh kedua insan sejenis itu. Clara Ng juga 
tidak secara langsung menampilkan siapa yang menjadi sosok "pria" dalam hubungan sejenis tersebut namun dengan pemaparan halus dan pengkategorian sosok yang tidak langsung dengan alur yang menarik membuat pembaca dengan sendirinya dapat mengetahui pribadi dari kedua tokoh utama tersebut.

Untuk mengungkap lebih dalam tentang lesbian dalam novel Gerhana Kembar, maka peneliti menggunakan pendekatan semiotik yang bertujuan untuk mengupas makna-makna yang tersembunyi dalam sebuah karya sastra, dan akan membantu pembaca dalam memahami lebih jelas mengenai karya sastra tersebut. Semiotik yang digunakan berdasarkan pandangan Roland Barthes, mengenai simbol dan makna yang digunakan untuk mengupas lesbianisme dalam novel Gerhana Kembar karya Clara $\mathrm{Ng}$.

Dengan mengidentifikasi makna-makna simbol lesbian dalam novel Gerhana Kembar karya Clara $\mathrm{Ng}$ ini kita dapat mengambil nilainilai pendidikan yang terkandung di dalamnya, dimana dengan diketahuinya simbol-simbol lesbian dapat menjadi acuan atau patokan untuk orang-orang terdekat kita bagaimana melakukan pengawasan tentang perilaku yang hampir mendekat ke arah lesbian tersebut.

Dengan demikian kita dapat menghindarkan orang-orang terdekat kita terhadap perilaku lesbian, Untuk itu peneliti mengangkat judul mengenai Simbol Lesbian dalam Novel Gerhana Kembar karya Clara $\mathrm{Ng}$.

\subsection{Rumusan Masalah}

Masalah dalam penelitian ini yaitu: a. Bagaimanakah Simbol Lesbian dalam Novel Gerhana Kembar karya Clara $\mathrm{Ng}$ ?

b. Bagaimanakah Hubungan Lesbian terhadap nilai agama dan sosial dalam Novel Gerhana Kembar karya Clara $\mathrm{Ng}$ ?

\subsection{Tujuan Penelitian}

Untuk mengetahui dan mendeskripsikan Simbol Lesbian dalam Novel Gerhana Kembar karya Clara $\mathrm{Ng}$ dan hubungan lesbian terhadap nilai agama dan sosial.

\subsection{Manfaat Penelitian}

Manfaat dari penelitian ini adalah untuk memberikan tambahan pengetahuan semiotik dalam karya sastra khususnya Novel serta mampu memahami simbol-simbol dalam setiap analisis teks sastra. Selain itu Penelitian ini memberikan pengetahuan tentang lesbianisme yang dapat dilihat melalui simbol-simbol dan tanda-tanda dalam novel sehingga melalui makna yang terkandung dalam pesan yang disampaikan dapat memberikan referensi bagi masyarakat.

\subsection{Batasan Operasional}

1. Semiotik adalah studi untuk mengambil berbagai sistem tanda seperti substansi dan batasan, gambar-gambar, berbagai macam gesture, berbagai suara music, serta berbagai obyek, yang menyatu dalam system of significance.

2. Simbol merupakan tanda yang makna representamen-nya diberikan berdasarkan konvensisosial.

3. Novel adalah bentuk prosa yang berisi tentang kehidupan manusia, melalui tokoh yang memiliki

263 | Jurnal BASTRA (Bahasa dan Sastra), Vol. 4 No. 2, Edisi April 2019/e-ISSN: 2503-3875/ http://ojs.uho.ac.id/index.php/BASTRA 
watak-watak tertentu dengan menampilkan berbagai aspek kehidupan.

4. Perbuatan homoseksual / Lesbian (homosexual acts) atau perilaku homoseksual (homosexual behavior) mengacu pada kegiatan atau perilaku seksual antara dua orang yang berjenis kelamin sama.

\section{KAJIAN PUSTAKA}

\subsection{Semiotik}

Teew (1984: 6) mendefinisikan semiotik adalah tanda sebagai tindak komunikasi dan kemudian disempurnakan menjadi model sastra yang mempertanggungjawabkan semua faktor dan aspek hakiki untuk pemahaman gejala susastra sebagai alat komunikasi yang khas di dalam masyarakat mana pun. Menurut Pradopo (2013: 121), semiotik merupakan sistem ketandaan yang berdasarkan atau ditentukan oleh konvensi (perjanjian masyarakat).

\subsection{Tinjauan Tentang Simbol}

Menurut Hartoko dan Rahmanto (1998) dalam Sobur (2004:155) secara etimologis simbol (symbol) berasal dari kata Yunani "sym-ballin" yang berarti melemparkan bersama sesuatu (benda, perbuatan) dikaitkan dengan suatu ide. Herusatoto (2000:10) dalam Sobur (2004:155) juga menyebutkan bahwa ada juga sebagian orang yang menyebutkan simbol dengan istilah "symbolos" yang berarti tanda atau ciri yang memberitahukan sesuatu hal kepada seseorang.

\subsection{Semiotik Menurut Roland Barthes}

Semiotika Barthes tersusun atas tingkatan-tingkatan sistem bahasa. Umumnya Barthes membuatnya dalam dua tingkatan bahasa. Bahasa tingkat pertama adalah bahasa sebagai obyek dan bahasa tingkat kedua yang disebut dengan meta bahasa. Bahasa ini merupakan suatu sistem tanda yang memuat signifier (penanda) dan signified (petanda). Sistem tanda kedua terbangun dan menjadi penanda dan penanda tingkat pertama berubah menjadi petanda baru yang kemudian memiliki penanda baru sendiri dalam suatu sistem tanda baru dalam taraf yang lebih tinggi.

Sistem tanda pertama kadang disebut sebagai denotasi atau sistem termilogi, sedangkan sistem tanda kedua disebut sebagai konotasi atau sistem retoris atau mitologi. Biasanya beberapa tanda denotasi dapat dikelompokkan bersama untuk membentuk suatu konotasi tunggal; sedangkan petanda konotasi berciri sekaligus umum, global, dan tersebar. Petanda ini dapat pula disebut fragmen ideologi. Petanda ini memiliki komunikasi yang sangat dekat dengan budaya, pengetahuan, dan sejarah. Dan dapat dikatakan bahwa "ideologi" adalah bentuk petanda konotasi dan "retorika" adalah bentuk konotasi (Barthes, 1967: 91-92).

\subsection{Kode Semiotika Roland Barthes}

Lima kode yang ditinjau Roland Barthes dalam Kaelan, (2009: 200) adalah kode hermeneutik (kode tekateki), kode semik (makna konotatif), kode simbolik, kode proaretik (logika tindakan), dan kode gnomik atau kode kultural yang membangkitkan suatu badan pengetahuan tertentu. Kode pertama berhubungan dengan penafsiran di mana teka-teki dan kebingungan harus dipecahkan, dalam rangka memeperoleh kebenaran. Kode kedua berhubungan dengan hakikat konotasi yang dikaitkan dengan peristiwa dan tokoh-tokoh. Kode 
ketiga berhubungan dengan polarisasi dan antitesis, dalam rangka menemukan multivalensi, bahkan perlawanan. Kode keempat berhubungan dengan aksi naratif yang dapat terjadi dalam beragam sekuen. Kode kelima berhubungan dengan semua referensi yang dihasilkan oleh masyarakat (Raman Selden, 1986: 7677; dalam Ratna, 2009: 260).

\subsection{Kajian Tentang Lesbianisme}

Faderman (dalam Oetomo, 2003: 34) mengatakan bahwa kata lesbian menggambarkan suatu hubungan di mana perasaan paling mendalam serta kasih sayang terjalin di antara dua perempuan. Hubungan seksual sedikit atau banyak mungkin terjadi di antara mereka, atau mungkin sama sekali tidak terjadi. Kedua perempuan itu lebih suka menjalani hidup bersama dan berbagi pengalaman yang sama.

Zimmerman (dalam Oetomo, 2003:173) juga mengemukakan bahwa lesbianisme adalah kekuatan yang melawan definisi kaku dan oposisi terkutub, diekspresikan melalui istilah jurang, ruang, penghancuran, hal-hal yang eksperimental, penghancuran radikal, interogasi dan seterusnya. Theresia Oki Mega Novena dalam skripsinya pernah menuliskan terdapat berbagai macam istilah yang digunakan untuk menyebut kelompokkelompok lesbian yaitu.

a. High femme atau lipstick lesbian adalah wanita yang tampak feminin secara stereotip (gincu, riasan, sepatu tumit tinggi, pakaian berjumbai dan lain-lain).

b. Femme, wanita yang memiliki penampilan feminim.

c. Soft butch, wanita yang berpenampilan lebih tidak jelas dari jenis kelaminnya. d. Stone butch, cenderung berpenampilan maskulin dan mungkin menyukai penetrasi vagina.

\subsection{Nilai Sosial Dalam Karya Sastra}

Nilai sosial adalah nilai yang mendasari, menuntun dan menjadi tujuan tindakan dan hidup sosial manusia dalam melangsungkan, mempertahankan dan mengembangkan hidup sosial manusia (Amir, dalam Sukatman, 1992:26). Nilai sosial merupakan norma yang mengatur hubungan manusia dalam hidup berkelompok. Norma sosial itu merupakan kaidah hubungan antar manusia, yang merupakan kaidah yang melandasi manusia untuk menyesuaikan diri terhadap lingkungan geografis, sesama manusia, dan kebudayaan alam sekitar. Karena kaidah itu melandasi kegiatan hidup kelompok manusia, maka dapat dikatakan nilai sosial merupakan petunjuk umum ke arah kehidupan bersama dalam masyarakat (Suparlan, 1983:142). Dari pendapat tersebut dapat dipahami bahwa nilai sosial merupakan pedoman umum dalam bermasyarakat.

\subsection{Nilai Agama atau Nilai Religius \\ Dalam Karya Sastra}

Religiusitas memperlihatkan nafas intensitas jiwa, yaitu cita rasa yang merupakan kesatuan rasio dan rasa manusiawi ke dalam pribadi manusia (Mangunwijaya, 1988:12). Kesatuan rasa dan rasio itu selanjutnya dipakai manusia untuk berhubungan dengan Tuhan. Sedangkan agama (religi) lebih menunjuk pada kelembagaan kebaktian kepada Tuhan dan kepada "dunia atas" dalam aspeknya yang resmi, yuridis, peraturan-peraturan 
dan hukum-hukumnya, serta keseluruhan organisasi tafsir Alkitab dan sebagainya yang melingkupi segisegi kemasyarakatan.

Sastra sering memuat nilainilai religiusitas. Hal demikian terjadi karena pada awalnya semua sastra adalah religius (Mangunwijaya, 1988:11). Artinya, semula sastra lahir untuk acara-acara kebaktian manusia kepada Tuhan, sehingga sastra hadir bersamaan dengan upacara keagamaan tertentu. Melalui sastra manusia ingin mendekat dan menyatu dengan Tuhan lewat seni (unio mistico). Oleh sebab itu, seperti dikatakan oleh Wellek dan Werren (1989:109), sastra memuat norma kehidupan masyarakat, nilai religiusitas, tradisi dan mitos, terutama dalam sastra masyarakat primitif. Karena itu muncullah istilah sastra religius karena dalam sastra memang sering terdapat nilai religius.

\section{METODE PENELITIAN}

\subsection{Jenis dan Metode Penelitian}

Jenis penelitian yang akan digunakan dalam penelitian ini adalah penelitian kepustakaan, yakni penelitian yang didukung oleh referensi baik berupa teks novel maupun sumber buku penunjang lainnyayang mencakup masalah dalam penelitian ini.

Penelitian ini menggunakan metode deskriptif kualitatif. Penelitian kualitatif selalu bersifat deskriptif, artinya data yangdianalisis dan hasil analisisnya berbentuk deskripsi fenomena. Metode kualitatif memberikan perhatian terhadap data alamiah, data dalam hubungannya dengan konteks keberadaannya.

\subsection{Data dan Sumber Data}

Data dalam penelitian ini adalah kata-kata, percakapandan kalimat dalam bentuk ungkapan yang mengandung tanda dan simbol lesbianisme dalam novel Gerhana Kembar karya Clara Ng.Sumber data yang digunakan dalam penelitian ini adalahnovel Gerhana Kembar karya Clara $\mathrm{Ng}$, penerbit Balai Pustaka, cetakan ketiga. Tahun terbit 2015, warna sampul hitam dan kunign dengan judul berwarna hitam muda dan putih, gambar sampul depan berupamenara dan Gerhana kembar, Jumlah 358 halaman, ISBN: 978-60203-1878-5.

\subsection{Teknik Pengumpulan Data}

Teknik pengumpulan data menggunakan teknik membaca, simak, dan catat. Teknik membaca yang dilakukan secara berulang-ulang dengan membaca data primer yaitu Gerhana Kembar karya Clara Ngkemudian disimak secara cermat teliti dan terarah terhadap data primer untuk memperoleh data kata leksikal, frasa, klausa, kalimat, ungkapan dan sejenisnya yang mengandung tanda dan simbol lesbianisme Gerhana Kembar karya Clara Ng. Dari hasil penyimakan kemudian dilakukan pencatatan data beserta kode sumber.

\subsection{Teknik Analisis Data}

Metode analisis data pada penelitian ini dilakukan dengan menggunakan pendekatan semiotik menurut Roland Barthes melalui tahap-tahap sebagai berikut:

1. Mengidentifikasi simbol-simbol lesbianisme dalam novel Gerhana Kembar karya Clara Ng.

2. Mengklasifkasi simbol-simbol lesbianisme dalam novel Gerhana Kembar karya Clara $\mathrm{Ng}$ berdasarkan pendekatan semiotik menurut Roland Barthes. 
3. Menafsirkan kembali seluruh data.

Teknik analisis data pada penelitian ini menggunakan pendekatan semiotik Roland Barthes. Data yang terkumpul kemudian diinterpretasikan sehingga terjalin antarstruktur yang saling berkaitan. Hasil yang diperoleh berupa uraian penjelasan. Selanjutnya data-data dikaji berdasarkan teori semiotika pendekatan pendekatan semiotik Roland Barthes tentang simbol dan makna sebagai kesimpulan dari analisis tanda dan simbol dalam Gerhana Kembar karya Clara Ng.

\section{HASIL DAN PEMBAHASAN}

\subsection{Analisis Simbol Lesbian dalam Novel Gerhana Kembar Karya Clara Ng.}

Dalam penelitian ini, peneliti menganalisis tanda berdasarkan objeknya. Yang diteliti adalah bagianbagian dialog maupun monolog yang mengandung pesan bermakna lesbianisme. Dari bagian-bagian tersebut, diteliti mana yang merupakan ikon, indeks, maupun simbol dari tanda-tanda yang memuat pesan untuk menginterpretasikan makna yang terkandung dalam pesan, yang ingin disampaikan oleh pengarang novel Gerhana Kembar ini. Untuk menjawab semua itu, ada 5 kode semiotika yang di tinjau Roland Barthes dalam Kaelan, (2009:200) yakni kode hermeneutic (kode tekateki), kode semik (makna konotatif), kode simbolik, kode proaretik (logika tindakan), dan kode Gnomik atau kode kultural yang membangkitkan suatu badan pengetahuan tertentu,untuk lebih jelasnya kita simak dalam penjelasan berikut ini:

\subsubsection{Kode Hermeneutik atau Kode Teka-Teki}

"Hebat, cepat sekali!" seru Henrietta. Tatapannya terpaku kepada Fola. Ada sesuatu yang menarik tentang perempuan ini, Henrietta tidak dapatmenjabarkan perasaannya. (Hal 51)

Berdasarkan data tersebut, katakata Henrietta menunjukkan sebuah pertanyaan di benaknya dari rasa kagum Henrietta pada Fola, karena sikap Fola yang cekatan. Tidak banyak perempuan yang bersikap cekatan, biasanya masyarakat menganggap seorang perempuan selalu lambat dalam bertindak. Tatapan Henrietta kepada Fola adalah tanda dari ketertarikan Henrietta pada Fola saat mereka bertemu pertama kali. Ada sesuatu yang membuat Henrietta tertarik pada Fola, tetapi dia tidak mengetahui apa yang membuatnya tertarik.

\subsubsection{Kode Semik atau Kode Konotatif}

"Henrietta tak berhenti memandangi Fola. Kecantikan Fola tidak seperti perempuan klasik yang mempunyai tulang pipi tinggi maupun leher yang jenjang. Ada bagian wajah Fola yang membundar seperti bulan purnama, tapi kelembutan sudut inilah yang membuat wajahnya menawan dan halus. Matanya yang dipenuhi bulu mata panjang, dua lesung pipit, serta kulit putih empuk menjadi bingkai daya tarik yang sangat perempuan". (Hal 68)

Berdasarkan data tersebut, Ada bagian wajah Fola yang membundar seperti bulan purnama adalah kode konotasi bahwa Henrietta menggambarkan sosok Fola sebagai sosok bulan purnama yang mempunyai bentuk lingkaran yang 
sangat sempurna dan selalu meneranginya seperti halnya bulan purnama yang bercahaya dan selalu menerangi gelapnya malam. Henrietta merasa Fola memiliki daya tarik yang khas dan berbeda dari perempuan lain.

\subsubsection{Kode Simbolik}

Kode simbolik adalah kode yang menawarkan "kontras" atau "antitesis" pada sebuah teks. Seperti siang-malam, feminin-maskulin, dan terbuka-tertutup.

"Ada dua warna. Hijau dan Cokelat." 'Hijau mengingatkanku pada daun dan tetumbuhan."

"Kalau begitu pilih yang warna cokelat?"

"Ah, yang hijau saja.

Lho, Katanya mengingatkanmu pada.....

"Tidak, Fola Tertawa riang. "Hijau Warna kesayanganku.

"Apa warna kesayanganmu?'

"Hm,"Henrietta berdeham. " $A k u$ menyukai warna kuning,

"Kenapa Kuning?"'

Mudah. Karena Bintang warna kuning. Matahari berwarna kuning. Emas warna kuning.(Halaman 56)

Berdasarkan data tersebut, Henrietta dan Fola menyimbolkan bahwa diri mereka lesbian, lewat warna kesukaan yang mereka sebutkan berdasarkan maknanya. Fola menunjukkan terhadap warna kesukaannya yang hijau di karenakan hijau mengingatkannya pada daun dan tumbuhan, sementara itu simbol warna kuning sebagai warna bintang atau matahari yang di sebutkan Henrietta sebagai warna kesukaannya karena merupakan warna bintang ataupun matahari.
Lambang 8 warna dalam simbol pelangi yang digunakan kaum LGBT mempunyai makna tersendiri dan sejarahnya. Dimana warna tersebut di cetuskan pada tanggal 25 Juni 1978 di San Fransisco, Amerika Serikat oleh seorang aktivis LGBT Gilbert Baker saat dilaksanakannya parade hari kebebasan kaum LGBT. Arti dan makna tersendiri yang dimaksud adalah warna Pink untuk seksualitas, Merah untuk kehidupan, Orange untuk penyembuhan, kuning untuk bintang dan matahari, hHijau untuk alam, Biru kehijauan untuk seni, Biru untuk perdamaian, dan Ungu untuk semangat.

\subsubsection{Kode Proaretik atau Kode Tindakan}

Lalu, tiba-tiba, Henrietta mengulurkan tangan ke depan, melingkarkan tangannya tepat pada bahu Fola, memeluknya erat, dan mencium rambut Fola tepat di ubunubun. Ini lebih berupa gerakan spontan daripada ciuman lembut penuh kasih sayang. (Hal 70)

Berdasarkan data tersebut, tindakan Henrietta yang memeluk Fola dan mencium rambutnya adalah ungkapandari rasa sayang Henrietta pada Fola. Saat itu, Henrietta mulai menyukaiFola. Sikap Fola yang lemah lembut dengan wajah yang manis membuat Henrietta merasa tertarik, dan tindakan mencium rambut sesama jenis merupakan hal yang tidak wajar dilakukan oleh sesama jenis yang sedang saling berpelukan.

\subsubsection{Kode Gnomik atau Kode Kultural}

"Fola ingin menolak, tapi ibunya mendesak. Saat itu usia Fola mendekati angka dua puluh tiga tahun, dan ibunya sudah cemas Fola akan jadi perawan tua jika tidak 
cepat-cepat mencari calon suami". (Hal 189)

Berdasarkan data tersebut, sikap ibu Fola yang ingin menjodohkan Fola dengan Erwin adalah ungkapandari rasa ketakutan yang dirasakan oleh ibu Fola karena Fola belum jugamemiliki seorang pacar. Ibu Fola tidak ingin Fola disebut sebagai perawan tua. ini menjadi sesuatu pemikiran umum dalam budaya masyarakat Jakarta pada masa antara 1960 sampai 1982 itu bahwa setiap ibu yang menganggap anaknya telah beranjak dewasa maka akan dijodohkan secepatnya.

\subsection{Hubungan Lesbianisme terhadap Nilai Agama dan Nilai Sosial \\ 4.2.1 Hubungan Lesbianisme terhadap Nilai Agama}

Nilai agama merupakan ketentuan hidup yang bersumber dari Tuhan Yang Maha Esa. Isinya berupa perintah-perintah, ajaran, dan larangan. Lesbianisme ialah suatu orientasi seks yang mana perempuan menyukai sesama jenis perempuan. Berdasarkan hal tersebut, lesbianisme merupakan perilaku yang sangat menyalahi aturan agama, sebagaimana kita ketahui bahwa Indonesia adalah negara mayoritas Islam dan patuh terhadap agama-agama yang disahkan oleh hukum Indonesia. Tuntutan hak keadilan juga harus di barengi dengan tuntutan hak saling menghormati terhadap masyarakat. Di dalam agama-agama pun mereka juga tidak menerima akan kehadiran lesbianisme di Indonesia.

\subsubsection{Hubungan Lesbianisme terhadap Nilai Sosial}

Nilai sosial adalah nilai yang dianut oleh suatu masyarakat, mengenai apa yang dianggap baik dan apa yang dianggap buruk oleh masyarakat. Untuk menentukan sesuatu itu dikatakan baik atau buruk, pantas atau tidak pantas harus melalui proses menimbang.

Lesbianisme ialah suatu orientasi seks yang mana perempuan menyukai sesama jenis perempuan.

Dampak sosial yang akan dirasakan, seperti stigma-stigma buruk dari masyarakat kepada pengidap lesbianisme, dikucilkannya para pengidap lesbianisme. Sedangkan dampak sosial yang dirasakan masyarakat sekitar tentu akan terganggunya kehidupan bermasyarakat karena lesbianism. Lesbianisme bukanlah suatu kebiasaan atau budaya yang baik dalam kehidupan bermasyarakat di Indonesia. Lesbianisme adalah suatu kesalahan perasaan yang terjadi pada manusia yang seharusnya jatuh kepada lawan jenisnya, dan harus segera ditangani bagi para pengidap lesbian tersebut. Anggapan masyarakat mengenai lesbianisme adalah tindakan buruk, tindakan menyimpang, tidak sesuai dengan kebudayaan yang ada di Indonesia, dan sangat menyimpang dari ajaran agama.

Namun, Akhir-akhir ini Indonesia sedang dikejutkan oleh aksi para aktivis yang memperjuangkan hak-hak kaum LGBT ini. Dari mulai koran, majalah dan televisi sibuk memberitakan menggeliatnya gerakan tersebut yang mendesak pemerintah agar kaum mereka diakui secara sosial oleh masyarakat Indonesia. Aksi tersebut yang dipelopori oleh kaum Gay tersebut menjadi pemicu munculnya para aktivis yang bisa 
dikatakan hanya sekedar "ikut-ikutan" demi mendapatkan predikat pejuang identitas. Sadar atau tidak, permasalahan ini membuat masyarakat geram, karena perilaku penyimpangan seksual ini menyalahi aturan-aturan masyarakat dan agama, terlebih adanya sikap toleransi yang harus di junjung tinggi karena kaum mereka juga sama-sama manusia.

\section{PENUTUP}

\subsection{Kesimpulan}

Sebuah karya fiksi yang jadi, merupakan sebuah bangun cerita yang menampilkan sebuah dunia yang sengaja dikreasikan pengarang. Karya fiksi menampilkan dunia dalam kata, bahasa, dan menampilkan dunia dalam kemungkinan. Novel yang merupakan karangan fiksi, terkadang mengungkapkan sebuah realitas yang ada di sekitar kita.

Novel merupakan sebuah struktur organisme yang kompleks, unik, dan mengungkapkan sesuatu secara tidak langsung. Hal inilah, antara lain, yang menyebabkan sulitnya kita pembaca untuk menafsirkannya. Untuk itu, diperlukan suatu upaya untuk dapat menjelaskannya, dan biasanya, hal itu disertai bukti-bukti hasil kerja analisis. Kesimpulan yang berkenaan dengan makna lesbianisme yang menggunakan teori Roland Barthes adalah lesbianism dapat dilihat melalui 5 kode, yakni yang pertama adalah Kode Hermeneutik atau kode Teka teki yang menggambarkan asbabun nuzul atau sebab akibat terhadap perilaku lesbian antara Fola dan Henrietta. Kemudian yang kedua adalah berdasarkan kode konotatif yang memberikan kilasan makna terhadap ungkapan para pelaku lesbian yang ada dalam novel Gerhana Kembar. Yang ketiga adalah berdasarkan kode simbolik yang merupakan gambaran terhadap identitas atau simbol yang menandakan bahwa Fola dan Henrietta adalah seorang lesbian. yang ke empat adalah berdasarkan kode proaretik atau tindakan yang menggambarkan perilaku lesbian Fola dan Henrietta seperti adegan ciuman maupun pelukan. Dan yang terakhir adalah berdasarkan kode Gnomik yang menggambarkan identitas budaya dalam novel Gerhana Kembar

Selain itu, Lesbianisme sangat erat kaitannya terhadap nilai agama dan sosial. Hal ini telah dijelaskan bahwa dalam nilai agama perilaku lesbianisme sangat dilarang dan ditentang oleh agama, selain itu juga perilaku lesbianisme merupakan perilaku yang tidak sesuai dengan adat istiadat dalam masyarakat indonesia ini, sebagaimana yang kita ketahui bahwa negara kita adalah salah satu negara yang sangat memegang teguh pada adat istiadat.

\subsection{Saran}

\subsubsection{Bagi para Novelis atau Pembuat Novel}

Saat ini, novel mulai berkembang pesat. Banyak penulis novel anak muda yang mulai bermunculan. Penulis-penulis baru juga mulai berani mengungkapkan fakta-fakta yang tersembunyi dalam kehidupan masyarakat. Hanya saja keterangan yang dijelaskan dalam cerita sebuah novel terkadang kurang lengkap. Seperti dalam Novel Gerhana Kembar karya Clara Ng ini. Walaupun tema yang diusung adalah percintaan lesbian tetapi tidak 
diungkapkan latar belakang seseorang itu bisa menjadi lesbian. Padahal, di dalam sebuah peristiwa yang terjadi pastiada penyebabnya.

\subsubsection{Bagi Peneliti Selanjutnya}

Penelitian tentang makna semiotika dalam novel ini sekiranya belumlah lengkap. Hal ini dikarenakan apa yang dipaparkan dalam penelitian ini, tentu belum mencakup seluruh fakta yang ada. Oleh karena itu, penulis harapkan Penelitian selanjutnya dengan menggunakan metode analisa semiotika yang memungkinkan munculnya interpretasi baru, diharapkan mampu menambah cakrawala semiotika.

\section{DAFTAR PUSTAKA}

Aminuddin. 2014. Pengantar Apresiasi Karya Sastra. Bandung: Sinar Baru Algesindo.

Barthes, R. 1967. Elements Of Semiologi. London: JonathanCape.

Berger, Arthur Asa. 2010. TandaTanda dalam Kebudayaan Kontemporer. Yogyakarta: Tiara Wacana.

Clara, Ng. 2015. Gerhana Kembar. Jakarta: Gramedia Pustaka Utama.

Deddy, Mulyana dan Jalaluddin Rakhmat. 2006. Komunikasi AntarBudaya: Panduan Berkomunikasi dengan OrangOrang Berbeda Budaya. Bandung: Remaja Rosdakarya.

Jabrohim. 2014. Teori Penelitian Sastra. Yogyakarta: Pustaka Belajar.

Kaelan. 2009. Filsafat Bahasa Semiotika dan Hermeneutika. Yogyakarta: Paradigma.
Liliweri, Alo. 2001. Gatra-gatra Komunikasi AntarBudaya. Yogyakarta: Pustaka Pelajar.

Minderop, Albertine. 2005. Metode Karakterisasi Telaah Fiksi. Jakarta: Obor.

Nurgiantoro, Burhan. 2010. Teori Pengkajian Fiksi. Yogyakarta: Gajah Mada Universitas Press.

Oetomo, Dede. 2003. Memberi Suara pada yang bisu. Cetakan Ke 2. Yogyakarta: Pustaka Marwa.

Pradopo, Rahmat Djoko. 2012. Beberapa Teori Sastra, Metode Kritik, dan Penerapannya. Yogyakarta: Pustaka Pelajar.

Pradopo, Rahmat Djoko. 2012. Pengkajian Puisi. Yogyakarta: Pustaka Pelajar.

Rafiek. 2013. Pengkajian Sastra. Bandung: PT. Refika Adithama.

Ratna, Nyoman Kutha. 2008. Teori, Metode, dan Teknik Penelitian Sastra dan Strukturalisme hingga Postrukturalisme. Yogyakarta: Pustaka Pelajar.

Rusmana, Dadan. 2014. Filsafat Semiotika. Bandung: Pustaka Setia.

Siswantoro. 2016. Metode Penelitian Sastra. Yogyakarta: Pustaka Pelajar.

Sobur, Alex. 2004. Semiotika Komunikasi. Bandung: Remaja Rosdakarya.

Teeuw, A. 1984. Sastra dan Ilmu Sastra: Pengantar Teori Sastra. Jakarta: Pustaka Jaya.

Wellek, Rene dan Austin Waren. 2013. Teori Kesusastraan (Terjemahan oleh Budianta). Jakarta: Gramedia.

Zoest, Aart Van. 1996. Fiksi dan Nonfiksi dalam Kajian Semiotik. Jakarta: Intermasa. 